\title{
Mapping South African public health research (1975 - 2014)
}

\author{
B Poreau, $\mathrm{MD}, \mathrm{PhD}$ \\ Institut Santé Publique - Relations Internationales (Public Health - International Studies Institute), Rue E Pons, 69004, Lyons, France
}

Corresponding author: B Poreau (poreau_brice@yahoo.fr)

\begin{abstract}
Background. Since 1994, South Africa (SA) has faced up to the challenge of building a strong economy, to which public health provides an important underpinning.

Objectives. To map the scientific research in public health in SA after the end of apartheid and to present the links between the different financing/funding systems.

Methods. Bibliographic analyses utilising the Web of Science of papers published during the period 1975 - 2014, analyses of journals, most cited articles, authors, publication years, organisations, funding agencies, countries and keywords, and mapping of the relations between countries involved in public health research and of the Web of Science Categories using VOSviewer.

Results. I accessed 2246 articles published between 1975 and 2014, the majority of which were published after 2007. The main countries of research were the USA, SA, Switzerland and the UK, representing the main network collaborations. The relevant keywords were HIV, woman, child, program/programme, rural, tuberculosis, district and sex.

Conclusions. Public health research in SA reached a high level 16 years after the end of apartheid. The chief field that emerged was the spread of HIV, including mother-to-child transmission, and the policies applied to all districts of SA, through a network of institutions between the USA and SA.
\end{abstract}

S Afr Med J 2015;105(1):52-55. DOI:10.7196/SAMJ.8866

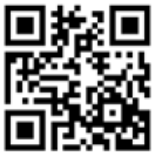

Since 1994 and the dawn of democracy in South Africa (SA), the country has made significant efforts to build one of the strongest economies in Africa. Development of the national health system, the foundation of which is the primary healthcare approach, has been a major goal ${ }^{[1]}$ aimed at the needs of the population. ${ }^{[2]}$ Public health covers the fields of infectious disease, parasitology, mental health, and organisation and financing of health facilities.

After 2007, the World Health Organization (WHO) presented several programmes on public health in SA. ${ }^{[1]}$ The main objectives of the 2008 - 2013 co-operation strategy were the fight against HIV, tuberculosis (TB) and malaria, the fight against motherto-child transmission (MTCT) of HIV, ${ }^{[1]}$ corresponding to Millennium Development Goals (MDGs) 4 - 6 , the need to strengthen health policies and to prevent and reduce disease, disability and premature death from non-communicable diseases, and the strengthening of surveillance systems.

The aim of this article is to analyse scientific publications on public health from SA during the period 1975 - 2014, in the context of the social situation in the country.

\section{Methods}

The Science Citation Index-Expanded (SCIE) database, accessed through the Web of Science platform from Thomson Reuters, was used. In the advanced search, the articles were obtained using this formula: TS=(public health AND South Africa) for the period 1975 - 2014. Each record was verified to ensure its relevance. This aim was to analyse differences before and after 1994. There were no restrictions regarding the document types.

The 'analysis results' function of the Web of Science was then performed. Journals, most cited articles, authors, countries, funding agencies, organisations, publication years and Web of Science Categories were extracted.

To evaluate the research networks between countries, after analysis by country, the records of each country were viewed and then the analysis was performed a second time in order to understand the links between the chosen country and the other countries. The mapping diagram was then developed.

To analyse the Web of Science Categories, the data were exported into a file 'analyze.txt'. This file can be read by the programme wc10.exe. It generated mapfiles for VOSviewer. ${ }^{[3]}$

Finally, several keyword (KW) researches were performed to find the main relevant topics. These analyses were to compare with former bibliometric studies in other fields. ${ }^{[3-5]}$

\section{Results}

I obtained 2246 records. There were 30 publications before 1994, but $1686 / 2246$ (72\%) after 2007 (Table 1).

The three authors with most records were Karl Peltzer, Alan Flisher and Diane

\begin{tabular}{|c|c|}
\hline Publication years & Records, $n$ \\
\hline 1987 & 1 \\
\hline 1991 & 6 \\
\hline 1992 & 12 \\
\hline 1993 & 11 \\
\hline 1994 & 11 \\
\hline 1995 & 14 \\
\hline 1996 & 16 \\
\hline 1997 & 28 \\
\hline 1998 & 40 \\
\hline 1999 & 34 \\
\hline 2000 & 35 \\
\hline 2001 & 43 \\
\hline 2002 & 48 \\
\hline 2003 & 39 \\
\hline 2004 & 63 \\
\hline 2005 & 75 \\
\hline 2006 & 84 \\
\hline 2007 & 131 \\
\hline 2008 & 154 \\
\hline 2009 & 177 \\
\hline 2010 & 225 \\
\hline 2011 & 263 \\
\hline 2012 & 297 \\
\hline 2013 & 315 \\
\hline 2014 & 124 \\
\hline
\end{tabular}


McIntyre, all three of whom were attached to SA academic institutions. The main journals were the South African Medical Journal (146/2 246), AIDS (89/2 246), BMC Public Health (64/2 246), PLoS One (50/2 246), Tropical Medicine and International Health (37/2 246) and the Bulletin of the World Health Organization (36/2 246).

The main research funding agencies were Wellcome Trust (UK, 55 records), the National Institutes of Health (USA, 37 records) and the National Research Foundation of South Africa (SA, 28 records) (Table 2). The UK, the USA and the European Union, as well as SA, are involved in financing public health research in SA.

The three most represented institutions in SA were the University of Cape Town (362/2 246), the University of the Witwatersrand (264/2 246) and the University of KwaZuluNatal (152/2 246).

The ten main countries involved were SA (1 246/2 246), the USA $(669 / 2246)$, the UK (395/2 246), Switzerland (130/2 246), Australia (101/2 246), Canada (94/2 246), France (93/2 246), Belgium (81/2 246), the Netherlands (69/2 246) and Kenya (55/2 246).

The networks between the main countries were mapped (Fig. 1). The scientific network concerning SA public health research, with the main countries involved, is described. The main arrow/link is between SA and the USA (with 236 records of 1246 linked to SA) as the most important collaboration. The second most important collaboration is between SA and the UK (186/1 246). Finally, the diagram illustrates three other important networks: SA-Switzerland (51/1 246), SA-Australia (48/1 246) and SA-Belgium (50/1 246).

Keyword analysis revealed the terms HIV (907/2 246 records), programme(s) and program(s) (638/2 246 records), woman (women) (466/2 246), child(ren) (438/2 246), rural (360/2 246), tuberculosis (269/2 246), district (209/2 246), sex (187/2 246), environment (131/ 2 246), malaria (121/2 246), mental health (118/2 246 records) and violence (102/2 246).

Finally, VOSviewer was used to map the Web of Science Categories (Fig. 2). The most important categories were Public, Environmental and Occupational Health, Infectious Diseases and Social Sciences Biomedical.

\section{Discussion}

According to my analysis, the majority of public health studies were undertaken in the post-apartheid era, ${ }^{[6-7]}$ very few having been published before 1994. At the end of the 1990s and in the first years of the 2000s, the themes were those found in this survey.

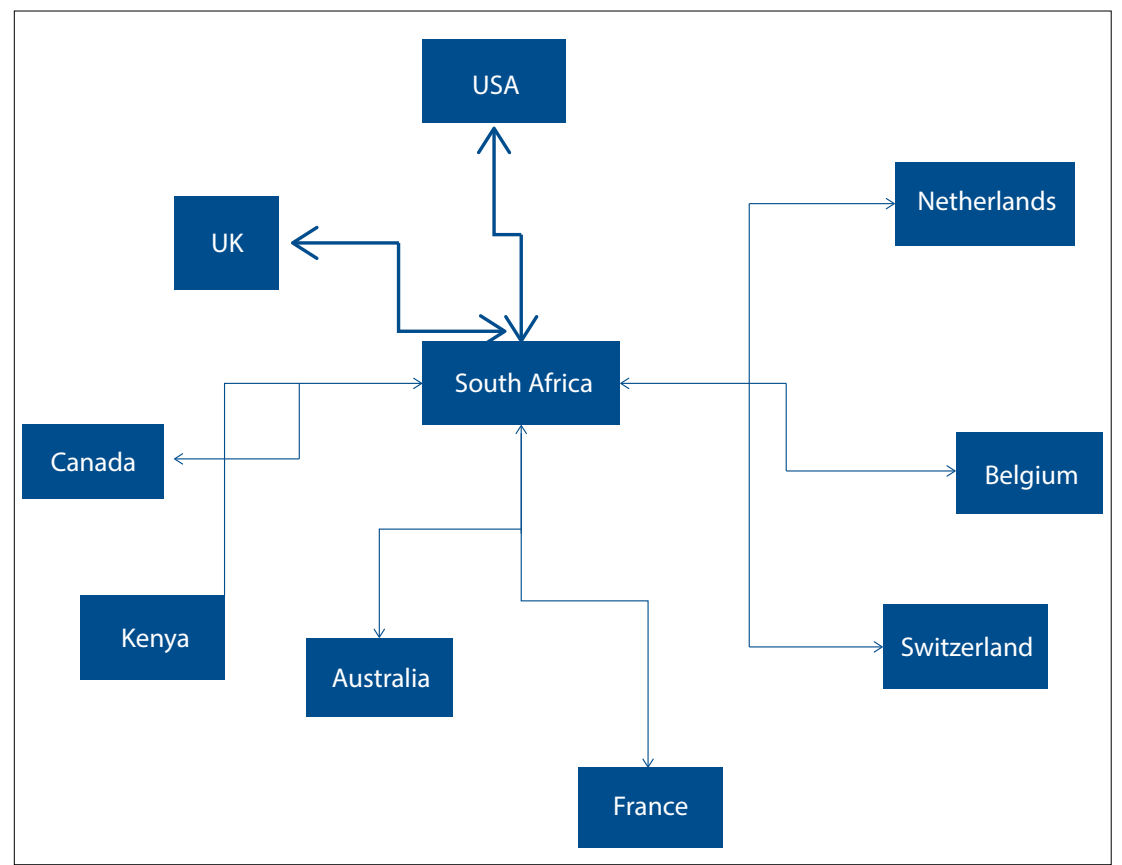

Fig. 1. Scientific networks in South African public health research and the main countries involved.

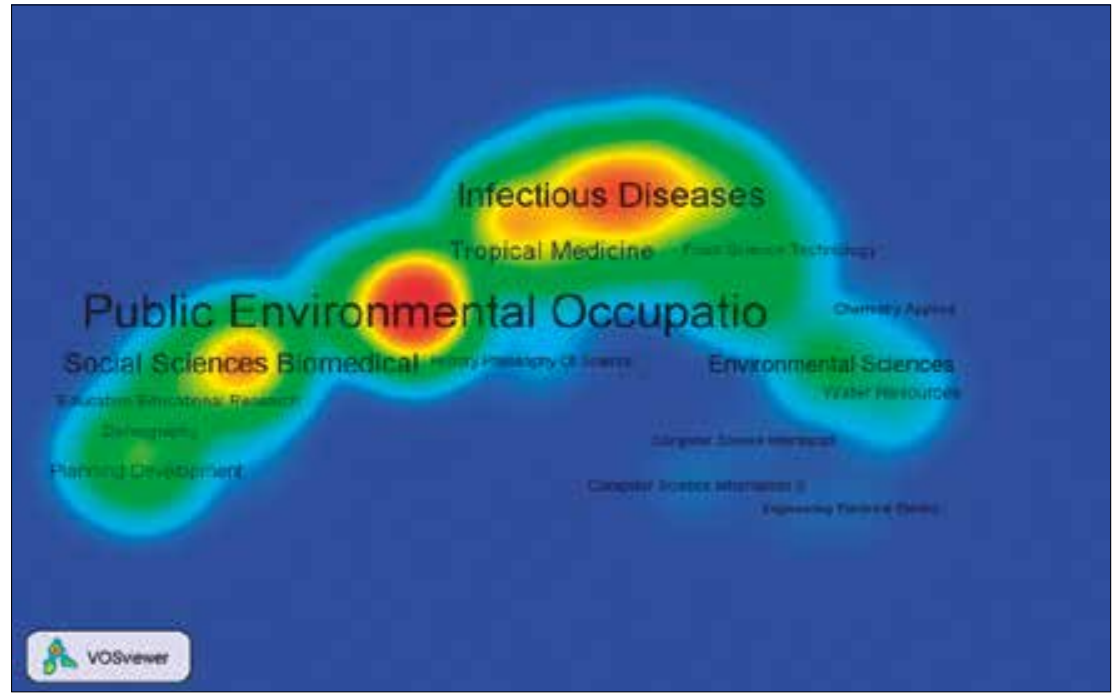

Fig. 2. Web of Science Categories mapped with VOSviewer. The most important categories are Public Environmental Occupational, Infectious Diseases and Social Sciences Biomedical.

\section{Table 2. Funding agencies ${ }^{*}$}

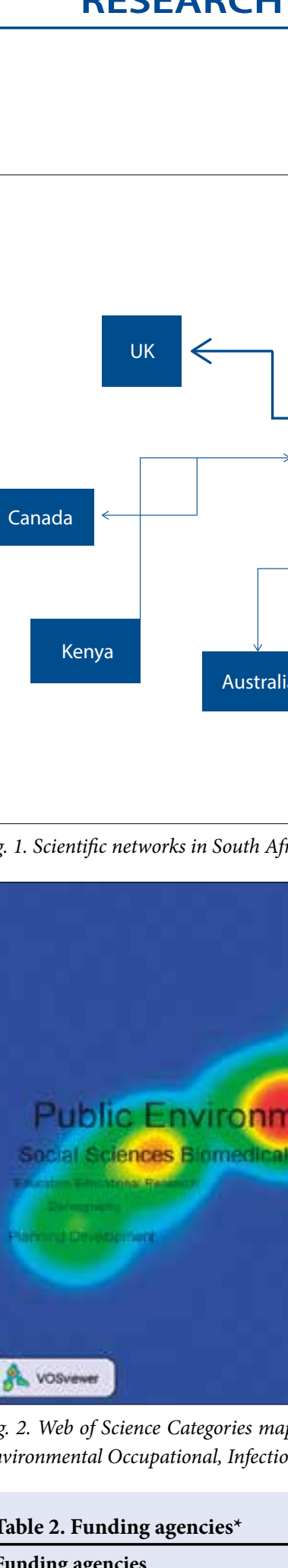

\section{Funding agencies}

Records, $n$

Wellcome Trust

55

National Institutes of Health

37

National Research Foundation

Bill and Melinda Gates Foundation

Medical Research Council of South Africa

Department of Health in South Africa

National Institute of Mental Health

Continued ... 
Table 2. (continued) Funding agencies ${ }^{\star}$

\begin{tabular}{|c|c|}
\hline Funding agencies & Records, $n$ \\
\hline National Research Foundation South Africa & 10 \\
\hline World Health Organization & 10 \\
\hline WHO & 9 \\
\hline Canadian Institutes of Health Research & 8 \\
\hline National Institute of Allergy and Infectious Diseases & 8 \\
\hline USAID & 8 \\
\hline Atlantic Philanthropies & 7 \\
\hline GlaxoSmithKline & 7 \\
\hline Medical Research Council South Africa & 7 \\
\hline South African Department of Health & 7 \\
\hline United States Agency for International Development & 7 \\
\hline United States Agency for International Development USAID & 7 \\
\hline University of the Witwatersrand & 7 \\
\hline US National Institutes of Health & 7 \\
\hline Water Research Commission WRC of South Africa & 7 \\
\hline Doris Duke Charitable Foundation & 6 \\
\hline Fogarty International Center & 6 \\
\hline Fogarty International Center National Institutes of Health & 6 \\
\hline Irish Aid & 6 \\
\hline National Institutes of Health NIH & 6 \\
\hline National Research Foundation NRF & 6 \\
\hline National Research Foundation NRF of South Africa & 6 \\
\hline United States National Institute on Aging & 6 \\
\hline Bristol Myers Squibb & 5 \\
\hline $\mathrm{CDC}$ & 5 \\
\hline Centers for Disease Control and Prevention & 5 \\
\hline Education Trust Fund of Nigeria & 5 \\
\hline FAS & 5 \\
\hline National Department of Health & 5 \\
\hline Stellenbosch University & 5 \\
\hline Swedish Council for Working Life and Social Research & 5 \\
\hline Swiss National Science Foundation & 5 \\
\hline UK Medical Research Council & 5 \\
\hline University of Fort Hare & 5 \\
\hline Wellcome Trust London UK & 5 \\
\hline Andrew W Mellon Foundation & 4 \\
\hline AUSAID & 4 \\
\hline CNPQ & 4 \\
\hline Department for International Development & 4 \\
\hline Human Sciences Research Council South Africa & 4 \\
\hline International Development and Research Centre & 4 \\
\hline International Development Research Centre & 4 \\
\hline John D and Catherine T MacArthur Foundation & 4 \\
\hline National Institute of Allergy and Infectious Diseases NIAID & 4 \\
\hline National Institute of Mental Health NIMH & 4 \\
\hline
\end{tabular}

HIV was prevalent in SA public health policy, ${ }^{[8]}$ and furthermore corresponded to MDG 6 (combat HIV/AIDS, malaria and other diseases).

The WHO focused on five objectives in SA in order to promote the MDGs. ${ }^{[1]}$ In this context, the main topics in this analysis were HIV, malaria, TB and mental health. This WHO emphasis in 2008 - 2013 corresponded to an increase in relevant public health publications (Table 1). The major collaboration was between the USA and SA (Fig. 1), while national public health policies were also significant. The National Department of Health (NDoH) developed the Negotiated Service Delivery Agreement 2010 - 2014, ${ }^{[2]}$ with four main objectives: increased life expectancy; reduction in maternal and child mortality rates (corresponding to MDGs 4 and 5); combating HIV and AIDS and decreasing the burden of disease from TB (corresponding to MDG 6); and strengthening health system effectiveness. The involvement of the $\mathrm{NDoH}$, and more generally the other government departments in the realm of public health, was greater than similar involvement in other African countries. ${ }^{[9]}$ This corresponds with the results of my analysis: the three most represented organisations, as well as the three authors most cited, were South African. Moreover, the National Research Foundation of South Africa was a major funding agency (Table 2).

This analysis demonstrated that the main field of public health concerned HIV spread and MTCT, so that new programmes were developed to address this transmission. ${ }^{[8]}$

I suggest that other public health issues, such as those in the field of mental health, might have been better represented. I noticed that the Mental Health Care Act No. 17 of $2002^{[2]}$ aimed to provide a legal framework for mental health and in particular the management of patients in mental health institutions, with emphasis on human rights. This Act corresponded to an increase in publications on mental health and raised questions about the mental health structures in SA. ${ }^{[10-11]}$

Finally, the Web of Science Category Public, Environmental and Occupational Health was dominant, ${ }^{[11]}$ with national policies correctly having had this focus (Fig. 2), reflecting the reality that SA remains an unequal society, with a Gini coefficient of 0.65 in 2011 . $^{[2]}$

\section{Study limitations}

The SCIE database provided the means for me to undertake this study. I acknowledge the limitation that, as a consequence, only publications appearing in this 
Table 2. (continued) Funding agencies*

Funding agencies

Records, $n$

National Science Foundation

North West University

PEPFAR

Pfizer

Research Foundation Flanders

Rockefeller Foundation

SIDA

US National Institutes of Health

UK Department for International Development

University of Cape Town

University of Michigan

US Centers for Disease Control and Prevention

US Department of Health and Human Services DHHS

Andrew W Mellon Foundation USA

Bank Netherlands Program Partnership

Boehringer Ingelheim

Canadian International Development Agency

Department for International Development DFID

Directorate General for Development Cooperation DGDC through the

Flemish Interuniversity Council VLIR UOS

European Developing Countries Clinical Trial Partnership Senior

Fellowship Award

Ford Foundation

Gilead Sciences

GlaxoSmithKline Biologicals

Health Canada

Health Economics and AIDS Research Division Heard at the

University of KwaZulu-Natal

Human Sciences Research Council

International Development Research Centre of Canada

Medical Research Council

Merck

MRC UK

National Health Laboratory Service Research Trust

National Institute of Allergy and Infectious Disease NIAID

National Institute on Drug Abuse

Pan American Health Organization

Pfizer Foundation

Poliomyelitis Research Foundation

President S Emergency Plan PEPFAR

Public Health Agency of Canada

Research Committee of The World Bank

SA National Research Foundation

Sanofi Pasteur

FAS = Forskningsrådet för arbetsliv och socialvetenskap (Swedish Council for Social and Work Life Research); AUSAID = Australian Agency for International Development; CNPQ = Conselho Nacional de Desenvolvimento Científico e Tecnológico (Brazilian Council for Scientific and Technological Development); PEPFAR = US President's Emergency Plan for AIDS Relief; SIDA = Swedish International Development Cooperation Agency; VLIR UOS = Vlaamse Interuniversitaire Raad - Universitaire Ontwikkelingssamenwerking (Flemish Inter-university Council - University Cooperation Development).

${ }^{*}$ Names of agencies are exactly as they appear in the records. database were used. It is therefore possible that participation of other countries, especially African countries, may have been underestimated in SA public health research. Other national databases could be used to develop the public health research links between SA and other African countries.

\section{References}

1. World Health Organization. WHO Country Cooperation Strategy 2008-2013. South Africa: WHO, 2009.

. Department of Health South Africa Annul Report 2011-2012. 2012. http://www.health.gov.za/docs/annual_reports/2012/ annualreport.pdf (accessed 16 November 2014).

3. Leydesdorff L, Carley S, Rafols I. Global maps of science based on the Leydesdorff L, Carley S, Rafols I. Global maps of science based on the
new Web-of-Science Categories. Scientometrics 2013;94(2):589-593. [http://dx.doi.org/10.1007/s11192-012-0784-8]

4. Law J, Whittaker J. Mapping acidification research: A test of the co-word method. Scientometrics 1992;23(3):417461. [http:// dx.doi.org/10.1007/BF02029807]

5. Chiu WT, Huang JS, Ho YS. Bibliometric analysis of severe acute respiratory syndrome related research in the beginning stage. Scientometrics 2004;61(1):69-77. [http://dx.doi.org/10.1023/ B:SCIE.0000037363.49623.28

6. Yach D, Tollman SM. Public health initiatives in South Africa in the 1940s and 1950s: Lessons for a post-apartheid era. Am J Public Health 1993-83(7):1043-1050. [http//dx doi orglo. Am J AJPH.83.7.1043]

7. Volmink JA, Metcalf CA, Zwarenstein M, et al. Attitudes of private general practitioners towards health care in South Africa. S Afr Med J 1993;83(11):827-833.

8. Coutsoudis A, Pillay K, Kuhn L, Spooner E, Tsai WY, Coovadia HM. Method of feeding and transmission of HIV-1 from mothers to children by 15 months of age: Prospective cohort study from Durban, South Africa. AIDS 2001;15(3):379-387. [http://dx.doi. org/10.1097/00002030-200102160-00011]

9. Poreau B. Mapping Rwanda public health research (1975-2014), Afr Health Sci 2014 (in press).

10. Hugo CJ, Boshoff DEL, Traut A, Zungu-Dirway N, Stein DJ. Community attitudes toward and knowledge of mental illness in South Africa. Soc Psychiatry Psychiatr Epidemiol 2003;38(12):715719. [http://dx.doi.org/10.1007/s00127-003-0695-3]

11. Mayosi BM, Lawn JE, van Niekerk A, Bradshaw D, Karim SSA, Coovadia HM. Health in South Africa: Changes and challenges Coovadia HM. Health in South Africa: Changes and challenges
since 2009. Lancet 2012;380(9858):2029-2043. [http://dx.doi. org/10.1016/S0140-6736(12)61814-5]

Accepted 4 September 2014 